\title{
Development of technology and formulation of cracker of high nutritional value
}

\author{
Anna Kovaleva ${ }^{1}$, Svetlana Galchenko ${ }^{1}$ and Alex Kolchanov ${ }^{2}$ \\ ${ }^{1}$ Associate professor, Southwest State University, 305004, 50 Let Oktyabrya str., 94, Kursk, Russia, \\ ${ }^{2}$ Design Engineer, Cashels Engineering Ltd, Aghamore, Cashels, Ballyhaunis, Co. Mayo, Ireland \\ e-mail:a.e.kovaleva@yandex.ru
}

\begin{abstract}
Human nutrition is one of the important factors that determine the health of the population. A fullfledged balanced diet creates conditions for normal physical and mental development, affects the body's ability to resist the effects of adverse environmental factors. The modern progressive direction of development of the confectionery industry is the creation of new technologies and the development of products of increased nutritional value. Today, a large number of product categories are represented in the structure of the snack market. One of the trends of recent years in the snack market is an increase in the consumption of natural snack products (nuts, seeds, dried fruits). In large part, this is due to the desire of consumers to live a healthy lifestyle. Therefore, products that carry the idea of proper and healthy nutrition are increasingly appearing on the market. This is what the developed product is - a cracker with enhanced nutritional value. In the course of the study, the technology and recipe of the cracker of said increased nutritional value were developed. This result was achieved by adding buckwheat flour and cheese to the recipe. The additives used allowed crackers to be made with high organoleptic and physico-chemical properties. At the same time, the optimal recipe was determined, in which wheat flower was replaced with $40 \%$ buckwheat flour. The analysis of the chemical composition and nutritional value of the developed cracker samples of increased nutritional value proved the validity of the additives introduced. Due to the introduction of these ingredients, the contents of B vitamins (B1, B2, B4, B6), dietary fiber, as well as other nutrients like magnesium, potassium, calcium, zinc, copper, molybdenum, sodium and chlorine, increased.
\end{abstract}

\section{Introduction}

In recent years, the production and consumption of flour confectionery products has increased. This segment of the product group leads the market due to its accessibility to the population and its traditional nature in the food structure. Among the wide range of confectionery products, the share of crackers is about $20 \%[1]$.

Currently, the problem of the lack of dietary fiber, vitamins, macro - and microelements in the diet of people is very urgent. In salted crackers made using traditional technology, it is customary to add cheese and rosemary, fried onions, Provencal herbs and seeds of various plants (flax, sesame and cumin), etc.

During the twentieth century, sweet crackers marketed as "Indians" appeared, with honey and sugar being added as well as dried fruits and nuts, to improve their taste.

The energy value of these crackers is quite high, but the vitamin and mineral composition is poor [2].

The addition of fats (butter, margarine) and/or dairy products to the cracker recipe increases the content of vitamins, which are vital substances that our body needs to maintain many of its functions [3].
The biological effect of vitamins is based on their role in metabolic processes and activation of oxidative reactions, which produce a large number of substances from carbohydrates and fats, which are then used by the body to generate energy and build tissues [4].

In recent years, crackers containing vitamin supplements have become very popular, but the search for nontraditional raw materials to increase the nutritional value that plays an important role in human health remains relevant [1].

Buckwheat flour was chosen as such a functional additive in the development of the cracker. Attention to buckwheat flour has increased in recent years. Its chemical composition and other positive properties are well studied. The research results of Russian and foreign scientists have revealed the high biological value of buckwheat flour and the possibility of its use in functional nutrition $[5,6]$.

The high degree of protein balance in terms of the content of essential acids makes buckwheat flour a particularly valuable product. Its proteins in terms of lysine and methionine content can be a substitute for meat, but are much easier to digest. In terms of leucine content, it is very close to beef, in valine - to milk, and in phenylalanine - to milk and beef [7]. 
Cheese was another ingredient in the cracker, containing essential amino acids including methionine, tryptophan, and lysine, as well as natural protein which contains about 20 amino acids, eight of which are essential.

Cheese protein contains amino acids that are similar to the proteins of human organs and tissues. For humans, such proteins are most useful.

The active ingredients of cheeses have a wonderful effect on the digestive glands and at the same time excite the appetite. All the nutrients that are present in cheese are absorbed by the human body almost $100 \%$. Dairy products, especially cheeses, are just a storehouse of vitamins A, D, E, B1, B2, B12, C, PP. These are vitamins that are good for the skin, vision, brain, and mucosa. Therefore, doctors recommend hard cheeses to children and pregnant women. Calcium, which is found in cheeses, is an important building block for bones and teeth.
Cheeses are very rich in protein. So, 70 grams of some cheeses contain the same amount of protein as 100 grams of meat and 100 grams of fish. Some of the most dietary cheeses that we sell are Cheese, Mozzarella, Brie, Feta. Their caloric content ranges from 300 calories. And the phosphoric acid contained in cheese is not called otherwise, but "the main engine of chemical reactions of all cells".

The purpose of the study was to develop a cracker of increased nutritional value with the addition of buckwheat flour and cheese.

\section{Methods}

A non-stick method was used to prepare the crackers with increased nutritional value. Figure 1 illustrates the technological process of preparing crackers more clearly. Preparation of a mixture of bulk components.

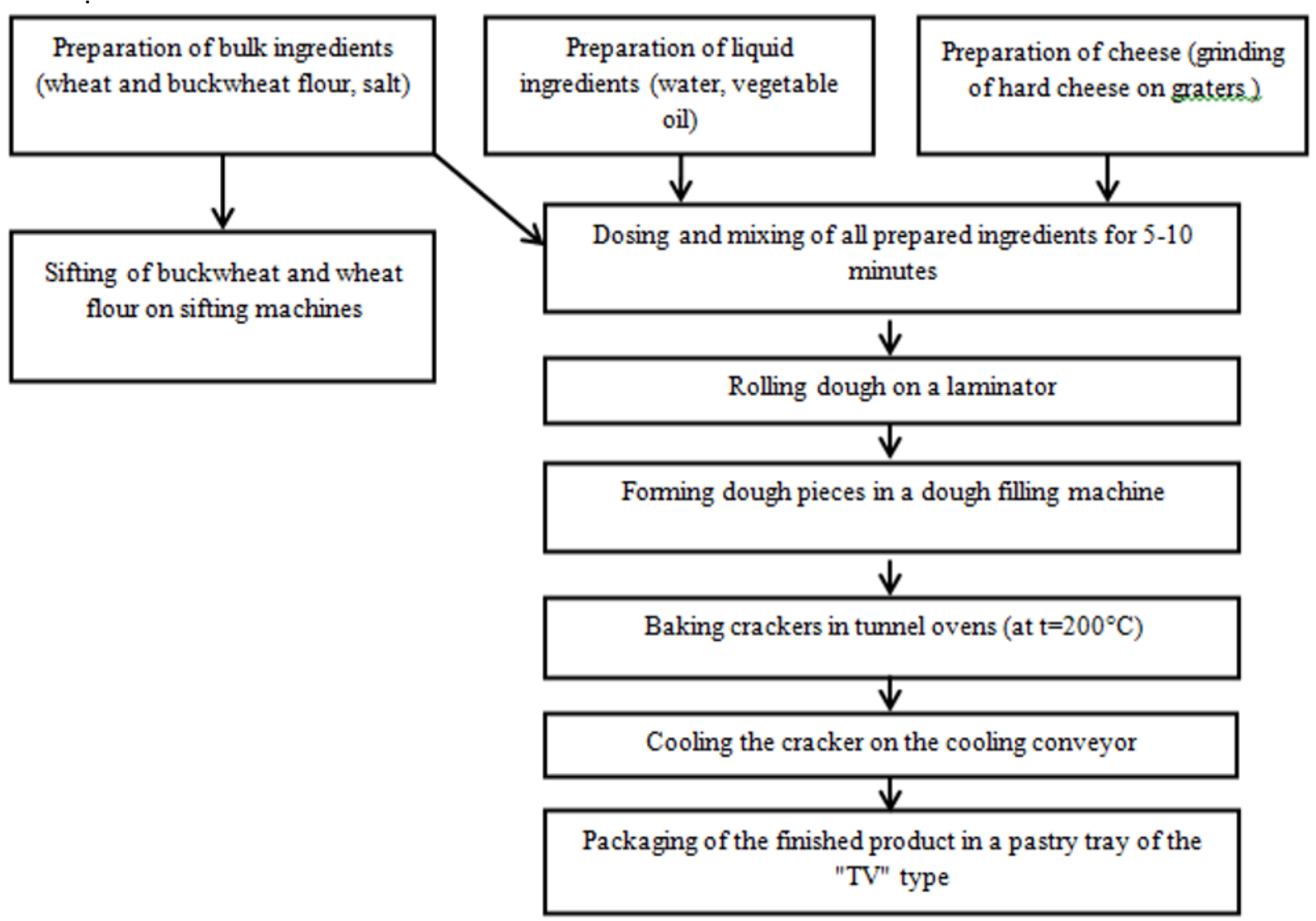

Fig 1. Technological scheme of production of cracker of increased nutritional value

The mixture is prepared in two stages: preparation of crumbs; preparation of a mixture of bulk components (buckwheat flour and wheat, crumbs). Flour is sifted to remove foreign particles. Additionally, during sifting, the flour is loosened, warmed, and saturated with air. Different kinds of sifting machines are used for sifting flour, the main component of which is a sieve. The crumb is prepared from returnable waste on a universal grinding machine of the "Rotomat" type or other specialized equipment. The finished crumb (particle size-0.8-1.2 mm) is fed through the scale to the mixer of bulk components. A set of bulk components for kneading a portion of dough is carried out on automatic scales. Preparation of a mixture of prescription components is carried out in a mixer for 3 minutes.

Then the liquid ingredients are prepared. The water should be at a temperature of $38-40{ }^{\circ} \mathrm{C}$. When mixing liquid components, the average temperature of the mixture should be $32-37{ }^{\circ} \mathrm{C}$. 
After that, the hard cheese is crushed on graters.

Next, all the ingredients (bulk and liquid) are mixed. The duration of kneading the dough depends on the rotational speed of the blades of said kneading machine, the properties of the flour and the temperature of the raw material, but on average it takes 15-30 minutes. The temperature of the dough for the cracker at the end of the batch should be $28-30{ }^{\circ} \mathrm{C}$.

After kneading, the cracker dough is laid out to relieve mechanical stresses in it. Also, the swollen and tightened gluten of the flour needs to be relaxed. If you do not hold the bed, the hardness of the final product increases, the shape of the finished crackers deteriorates, etc. The finished relaxed dough is rolled out and folded several times (that is, laminated) to give the finished cracker a layer and carefully rolled out to give it the necessary thickness before forming the dough pieces.

Test blanks are usually formed by the rotary method. The cracker rotor forms edges, a pattern on the surface, and through holes. The latter are necessary for a larger cracker, otherwise during the baking process, the moisture will not have time to evaporate in time and you will get a "pillow" in the center of the cracker.

Cracker baking is carried out in continuous or very rarely batch ovens. Baking a cracker is a combined baking-drying process. Baking of dough pieces is carried out in tunnel furnaces with mesh steel belts at a temperature of $200{ }^{\circ} \mathrm{C}$, in which after one minute in the surface, layers of the dough piece the temperature reaches $100^{\circ} \mathrm{C}$, and by the end of baking, up to 150$160^{\circ} \mathrm{C}$. The temperature of the central layers of the dough rises after one minute to $70{ }^{\circ} \mathrm{C}$, and by the end reaches $106-108{ }^{\circ} \mathrm{C}$. The total duration of baking crackers - 10-15 minutes

The consumption of crackers is approximately $26 \%$.

The baked products are cooled to give them mechanical strength, which allows them to remove products from the oven belts, without disturbing the shape of the products. First, the products are cooled in the chamber on the protruding part of the conveyor from the furnace to a temperature of $50-70{ }^{\circ} \mathrm{C}$, and then on the cooling conveyor to a temperature of $35-45^{\circ} \mathrm{C}$ for 6-8 minutes.

Then the crackers are delivered to the stacking conveyor, where the products are packed and packaged.

Three cracker recipes were developed based on the basic recipe for crackers [8] this was done by replacing a part of the wheat flour with buckwheat flour in amounts of 20\%,30\%, and $40 \%$, respectively.

\section{Results and discussion}

The quality indicators of the baked cracker samples were assessed using expert and organoleptic methods. The expert method is based on the fact that each of the 5 experts participating in the survey assigns a certain score to each of the criteria [9-15]. Each taster filled out the tasting cards, which were processed and the results are summarized in Table 1.

From the data obtained in Table 1, the best of the cracker samples of increased nutritional value in terms of organoleptic parameters is sample No. 3. In almost all indicators, the tasters gave it 5 points each. It had a regular shape, the surface without cracks and slightly rough. The product is a dark brown which is uniform over the entire surface; the appearance is baked, elastic; the aroma is characteristic of this cracker, with no foreign tastes, and a slight buckwheat flour and cheese smell. There are no traces of non-molten material in the product.

Table 1. Results of the study of organoleptic quality indicators with improved properties for consumers.

\begin{tabular}{|l|c|c|c|}
\hline $\begin{array}{c}\text { Quality } \\
\text { indicator }\end{array}$ & $\begin{array}{c}\text { Sample } \\
\text { No. 1 }\end{array}$ & $\begin{array}{c}\text { Sample } \\
\text { No. 2 }\end{array}$ & $\begin{array}{c}\text { Sample } \\
\text { No. 3 }\end{array}$ \\
\hline Taste & 4.4 & 4.6 & 5 \\
\hline Smell & 5 & 5 & 5 \\
\hline Color & 4 & 4.2 & 4.8 \\
\hline Consistency & 4 & 4.4 & 5 \\
\hline Form & 5 & 5 & 5 \\
\hline Surface & 4.8 & 4.8 & 4.8 \\
\hline Points total & 27.2 & 28 & 29.6 \\
\hline
\end{tabular}

In the sample of cracker No. 1 (with $20 \%$ buckwheat flour added), the shape is correct; the surface is slightly rough. The color of the product is slightly changed. The view in the fracture is baked, the porosity is uniform. According to the taste, all the tasters noted that the sample No. 1 has a weak taste, as well as a less uniform consistency, for which they reduced its points. The smell is pleasant, characteristic of this type of product.

The sample of cracker No. 2 (with $30 \%$ buckwheat flour added) has a triangular shape, regular, without cracks and damage to the corners and edges; the surface is slightly rough and oily. The color of the product is brown, with patches of cheese. The view in the fracture is baked, the porosity is uniform and uniform. According to the taste, all the tasters noted that the sample number 2 has a characteristic taste of cracker, but a weak taste of cheese and buckwheat flour, for which they reduced its points. The smell is characteristic of a cracker, without foreign odors.

The main physical and chemical parameters for crackers and biscuits are normalized by GOST (state standard) 14033-2015 "Cracker. General technical conditions", an analysis was conducted on the acidity, alkalinity, wetness, fat content in terms of dry matter and moisture content of the three developed cracker samples and the control sample with comparison of their physical/chemical properties, this was followed by the identification of the best samples for production at the enterprise. The results of the obtained studies are presented in Table 2.

Table 2. Results of the study of the physico-chemical quality indicators of the cracker of increased nutritional value and the control sample.

\begin{tabular}{|l|c|c|c|c|}
\hline $\begin{array}{c}\text { Quality } \\
\text { indicator }\end{array}$ & $\begin{array}{c}\text { Control } \\
\text { sample }\end{array}$ & $\begin{array}{c}\text { Sample } \\
\text { No. 1 }\end{array}$ & $\begin{array}{c}\text { Sample } \\
\text { No. 2 }\end{array}$ & $\begin{array}{c}\text { Sample } \\
\text { No. 3 }\end{array}$ \\
\hline Humidity, \% & 4.5 & 434 & 434 & 436 \\
\hline Acidity, deg. & 16 & 11 & 11 & 11 \\
\hline Alkalinity, \% & 278 & 275 & 28 & 28 \\
\hline $\begin{array}{l}\text { Mass fraction } \\
\text { of fat in terms } \\
\text { of dry matter, } \\
\%\end{array}$ & 25 & 18 & 18 & 18 \\
\hline Wetness, \% & 153 & 152 & 151 & 151 \\
\hline
\end{tabular}

According to the results of the study of the physicochemical quality indicators of the cracker samples of increased nutritional value and the control sample (Table 
2), the differences in the obtained indicators are insignificant and all are within the limits specified in the standard. So, based on the mass fraction of moisture content, which according to GOST (state standard)140332015 ranges from 3 to $8.5 \%$, this indicator in the studied crackers did not exceed $4.5 \%$ and was $4.5 \%$ in the control, in samples No. 1 and No. 2 - 4.34\%, in sample No. 3 $4.36 \%$.

In terms of "Acidity", all samples meet the requirements of the regulatory documentation and are: for the control sample - $1.6 \mathrm{deg}$. , for samples No. 1-No. 3$1.1 \mathrm{deg}$.

According to the indicator of "Alkalinity", all samples also meet the requirements of the regulatory documentation and are: for the control sample $-2.78 \%$, for sample No. 1-2.75 \%, for samples No. 2 and No. 3-2.8 $\%$.

On the basis of the indicator "Wetness" in this table, it can be seen that all samples comply with the regulatory documentation and are: for the control sample $-153 \%$, for sample No. 1-152 \%, for samples No. 2 and No. 3-151 $\%$. According to the regulatory documents, the wetness for the cracker should be at least $140 \%$.

The mass fraction of fat in terms of dry matter fully complies with GOST and is: for the control sample $-25 \%$, since butter was used in the control sample, and for samples No. 1-No. 3 - 18\%, since vegetable oil was used in these samples. According to regulatory documents, the mass fraction of fat in terms of dry matter should be at least $10 \%$ and not more than $26 \%$.

Based on the studies of the developed samples of crackers of increased nutritional value, it is clear that they comply with GOST (state standard) 14033-2015.

\section{Conclusions}

According to the results of the conducted research, the following conclusions can be drawn:

- for the production of crackers, a non-binary method is used, which will reduce the technological process;

- adding 50\% or more of buckwheat flour to the recipe of a cracker of increased nutritional value causes the product to have a specific taste and smell of buckwheat flour;

- the optimal dosage of buckwheat flour for obtaining a cracker with the desired properties is $40 \%$ of the weight of wheat flour.

\section{References}

1. T. V. Matveeva, Flour confectionery products of functional purpose. Scientific bases, technologies, recipes, 360 (2016)

2. A. E. Kovaleva, A. S. Ryazantseva, Development of the recipe for crackers enriched with vegetable raw materials, 157 (2019)

3. A. I. Dragilev, Ya. M. Sezanaev, Production of flour confectionery products: a textbook, 448 (2013)

4. V. Rumyantseva, D. Orekhova, O. Miller, Khleboprod. Unconventional raw materials in the technology of cracker production 340 (2009)
5. D. S. Mysakov, E. V. Kryukova, O. V. Chugunova, NAUKOVED. Study of the chemical composition of buckwheat flour and its effect in a mixture with wheat flour on the quality of bread 5 (7), (2015)

6. E. N. Molchanova, M. E. Saitova, G. G. Dubtsov, Quest. of Diet. Antioxidant activity of buckwheat flour, 2 (1), 65 (2011)

7. R. A. Fedorova, V. S. Volkov, V. Yu. Novikova, Izv. St.-Peter. Development of recipes and technologies of pasta with the addition of buckwheat flour 1 (46), 91 (2017)

8. A. P. Antonov, Collection of technological stan-dards: Collection of recipes for cakes, pastries, cupcakes, rolls, cookies, gingerbread, cakes and muffin products 720 (2000)

9. A. E.Kovaleva, E. A. Pyanikova, Vestnik VSUIT Evaluation of quality indicators of wheat bread enriched with secondary apple raw materials 1 (82), 200 (2020)

10. E. Bartkiene, V. Bartkevics, I. Pugajeva, V. Krungleviciute et al., The contribution of $P$. acidilactici, L. plantarum, and L. curvatus starters and L-(+)-lactic acid to the acrylamide content and quality parameters of mixed rye-Wheat bread $\mathbf{8 0}, 43$ (2017)

11. M. Przygodzka, M.K. Piskula, K. Kukurová, Z. Ciesarová et al. Cer. Scien. Factors influencing acrylamide formation in rye, wheat and spelt breads 65, 96 (2015)

12. A. Mihhalevski, I. Heinmaa, R. Traksmaa, T. Pehk et a 1. J. of agricult. and food chem. Structural changes of starch during baking and staling of rye bread $\mathbf{3 4}$ (60) 8492 (2012)

13. Wang D., Yeats T.H., Uluisik S., Rose J.K. et al. Fruit softening: revisiting the role of pectin // Trends in plant science 4 (23), 302 (2018)

14. R. Ciriminna, A. Fidalgo, R. Delisi, L. M. Ilharco et al. Agro Food Ind. HiTech. Pectin production and global market 5 (27), 17 (2016)

15. W. Zhang, P. Xu, H. Trends in Food Scien. \& Techn. Zhang Pectin in cancer therapy: A review 2 (44), 258 (2015) 